\title{
Finite Element Analysis of Damping Properties of High Strength Aluminum A356 Alloy Composite
}

\author{
Shiva Prasad, Shiva Kumar, Ch.Santosh Kumar Reddy
}

\begin{abstract}
Aluminum composites are in reality notably used as a piece of various programs due to their tremendous load to quality homes. Many studies works had been finished to ponder and improve the mechanical houses of aluminum mixes. The formation of alloying segments anticipate a fundamental component in choosing the properties of a mix. The eventual results of numerical systems have been recognized via and massive as they eagerly facilitate with the check comes to fruition. In the present evaluation a numerical examination contraption i.E., restrained section examination (FEA) is used. The paintings presented in this paper is away for the examination of effect of vibration traits of aluminum blends of various sport plans. The displaying and evaluation is finished the usage of ANSYS programming. A secluded assessment is carried out to recognize the vibration direct $i . E$., trademark repeat and mode shapes, of the cloth considered. The mode shapes and fashionable Recurrence receive a essential part within the framework Of dynamic machines. The consonant evaluation has been made to choose repeat traits. The examination software scrutinizes the information from the records archive shapes the information and makes the yield document containing the nodal migrations and nodal stretch estimations of various nerves. From the examination it's miles assumed that as the copper and silicon content material within the amalgams grows winding decreases then again. ANSYS comes about insist the smallest Modulus twisting and a definitive tractable strengthincaseofthe 380 mixes of 380 additions with the extension in copper and silicon content. Subsequently Al 380 amalgams show high-quality fine with least vibration.
\end{abstract}

Watchwords:Aluminum mixes, vibration characteristics, FEA

\section{INTRODUCTION}

Since the specific gravity of Aluminum is generally 2.7 $\mathrm{g} / \mathrm{cc}$, the composites of Aluminum be given an outstandingly immense part in mild weight machine fragments. Silicon, copper, magnesium, iron, manganese, and zinc are primary segments in Aluminum composites. The homes of these composites can be organized and these fast may be used as a bit of setup structuring with the bearings for diverse blends. Aluminum blends (or aluminum mixes; see spelling contrasts) are amalgams wherein aluminum (Al) is the ruling steel. The ordinary alloying segments are copper, magnesium, manganese, silicon, tin and zinc. There are two

Revised Manuscript Received on September 14, 2019.

Shiva Prasad, Assistant Professors/ Department of Mechanical Engineering. Siddhartha Institute of Technology and sciences, Narapally, Hyderabad, Telangana, India.

Mr. Shiva Kumar, Assistant Professors/ Department of Mechanical Engineering. Siddhartha Institute of Technology and sciences, Narapally, Hyderabad, Telangana, India.

Mr. Ch. SantoshKumar Reddy, Assistant Professors/ Department of Mechanical Engineering. Siddhartha Institute of Technology and sciences, Narapally, Hyderabad, Telangana, India. crucial plans, to be explicit tossing amalgams and molded mixes, the 2 of which are moreover subdivided into the characterizations warm treatable and non-warm treatable. Around eighty five\% of aluminum is used for made matters, for instance moved plate, foils and ejections. Cast aluminum composites yield commonsense things attributable to the low dissolving factor, despite the way that they usually have cut down flexible traits than made amalgams. The maximum fundamental solid aluminum composite structure is $\mathrm{Al}-\mathrm{Si}$, where the anomalous measures of silicon (4.Zero-13\%) upload to present superb tossing characteristics. Aluminum amalgams are commonly used as a piece of constructing structures and quantities where mild weight or disintegration obstruction is needed. Composites made usually out of aluminum have been basic in aeronautics developing since the creation of steel-wiped clean provider. Aluminummagnesium amalgams are both lighter than other aluminum composites and altogether less ignitable than mixes that comprise a full-size level of magnesium. Aluminum compound surfaces will increase a white, guarded layer of aluminum oxide every time left unprotected with the aid of anodizing and additionally adjust portray manner. In a wet location, galvanic disintegration can occur while an aluminum amalgam is about in electric contact with diverse metals with greater nice utilization potential outcomes than aluminum, and an electrolyte is obtainable that presents molecule exchange. Insinuated as one of a type metallic usage, this technique can occur as stripping or as intergranular disintegration. Aluminum mixes may be despicably heat treated. This reasons internal segment parcel, and the metal through then dissolves from the back to the front.

Aluminum blend systems are enrolled with The Aluminum Association. Various affiliations disseminate increasingly specific models for the create of aluminum amalgam, which include the Society of Automotive Engineers standards association, in particular its aeronautics regulations subgroups, and ASTM International

Building Use and Aluminum Alloys Properties

Aluminum mixes with a wide collection of houses are used as a bit of building systems. Composite structures are requested by a number of shape (ANSI) or with the aid of names displaying their vital alloying materials (DIN and ISO). Picking the right blend for a given application includes examinations of its flexibility, thickness, pliability, formability, capability, weldability, and disintegration

\section{Published By:}

Blue Eyes Intelligence Engineering 
obstruction, to provide some models. A succinct real define of blends and amassing advancements is given in Ref.[4] Aluminum amalgams are used widely in flying gadget in mild of their excessive caliber to-weight quantity. On the opposite hand, flawless aluminum metallic is excessively fragile for such makes use of, and it does not have the high versatility that is required for planes and helicopters.

\section{METHODOLOGY \& WRITING REVIEW}

This segment affords the past and cutting-edge occasions on the two broadly used $\mathrm{Al}$ amalgams viz., Al-Mg and Al$\mathrm{Mg}-\mathrm{Sc}$ mixes. Besides, a framework of various welding techniques, as an instance, FS, MIG, TIG and LB welding of $\mathrm{Al}-\mathrm{Mg}$ blends and of $\mathrm{Al}-\mathrm{Mg}-\mathrm{Sc}$ mixes are further proven.

\subsection{Cheerful Materials}

\subsubsection{Aluminum-Magnesium Alloy 5083}

Unadulterated aluminum yield push is $10 \mathrm{MPa}$ so to speak. The nature of $\mathrm{Al}$ is proper simple for his or her utility as helper substances. Regardless, including numerous alloying parts, for example, $\mathrm{Cu}, \mathrm{Mg}, \mathrm{Mn}$, and $\mathrm{Zn}$, the nature of the amalgam can be redesigned. Development of Magnesium constructs the pliable properties of the aluminum composite structure. The tempered state nature of AA5083 mix is round a hundred and fifty MPa, whilst, the character of this composite has been prolonged to over 250MPa through strain cementing techniques [Lloyd (1980)]. Among different alloying segments, Mg is observed to upgrade the disintegration opposition notwithstanding yield push. $\mathrm{Mg}$ shapes substitution stable route of action with $\mathrm{Al}$ as its atomic range is $12 \%$ greater than that of $\mathrm{Al}$ particle. The proximity of $\mathrm{Mg}$ improves first-rate and moreover adaptability. Least of $23 \mathrm{wt} \%$ flexibility is seen up to the extension of $6 \mathrm{wt} \%$ of $\mathrm{Mg}$ and higher attention over $6 \mathrm{wt} \%$ supposedly brings approximately issues in coping with. The yield stress of Al-Mg amalgam increases with $\mathrm{Mg}$ content for a toughened AA5083 as showed up with the aid of Fig.2.1. The twist depicts decrease in $\%$ prolongation as $\mathrm{Mg}$ content material additions. Another disclosures exhibit that the nearness of various segments in route of motion (for instance iron and manganese) can in like way supply a primary strengthening responsibility, gave that it very well can be saved in sport plan. Alloying elements in path of motion with aluminum have assorted fortifying responsibilities as confirmed up in Table 2.1.

Technique

Aluminum compound A356 composite Material

Substance Composition

Structure limits. 356.Zero: zero.25 Cu max, zero.20 to $0.45 \mathrm{Mg}, 0.35 \mathrm{Mn} \max , 6$.Five to 7.Five $\mathrm{Si}$, zero.6 Fe max, zero.35 $\mathrm{Zn} \max$, zero.25 Ti max, 0.05 different (each) maximum, zero. 15 others (absolute) max, bal Al. A356.0: $0.20 \mathrm{Cu} \max$, zero. 25 to $0.45 \mathrm{Mg}$, zero. $10 \mathrm{Mn} \max$, 6.Five to $7.5 \mathrm{Si}, 0.20 \mathrm{Fe} \max , 0.10 \mathrm{Zn} \max , 0.20 \mathrm{Ti} \max$, zero.05 different (each) maximum, 0.15 others (all out) max, bal Al. Result of surpassing debasement limits. High copper or nickel diminishes malleability and protection from intake. High iron declines satisfactory and versatility

\begin{tabular}{|c|c|} 
Mechanical Properties \\
\hline Property & value \\
\hline $0.2 \%$. Proof Stress (MPa) & 185 \\
\hline Tensile stress (MPa) & 230 \\
\hline Brinell Hardness & 75 \\
\hline Modulus of Elasticity & 71 \\
\hline Shear strength & 120 \\
\hline Elongation $(\%)$ & 2 \\
\hline
\end{tabular}

\section{APPLICATIONS \& RESULTS}

air pump components, automobile transmission case, fittings and manipulate the elements of air, water-cooled cylinder block

Other applications in which forged a tremendous potential and the ability to weld properly, stress tightness and resistance to corrosion is required rights.

A356.0: aircraft and engine control systems, nuclear power installations, and other packages where excessive mold enduring power or the necessary investment castings
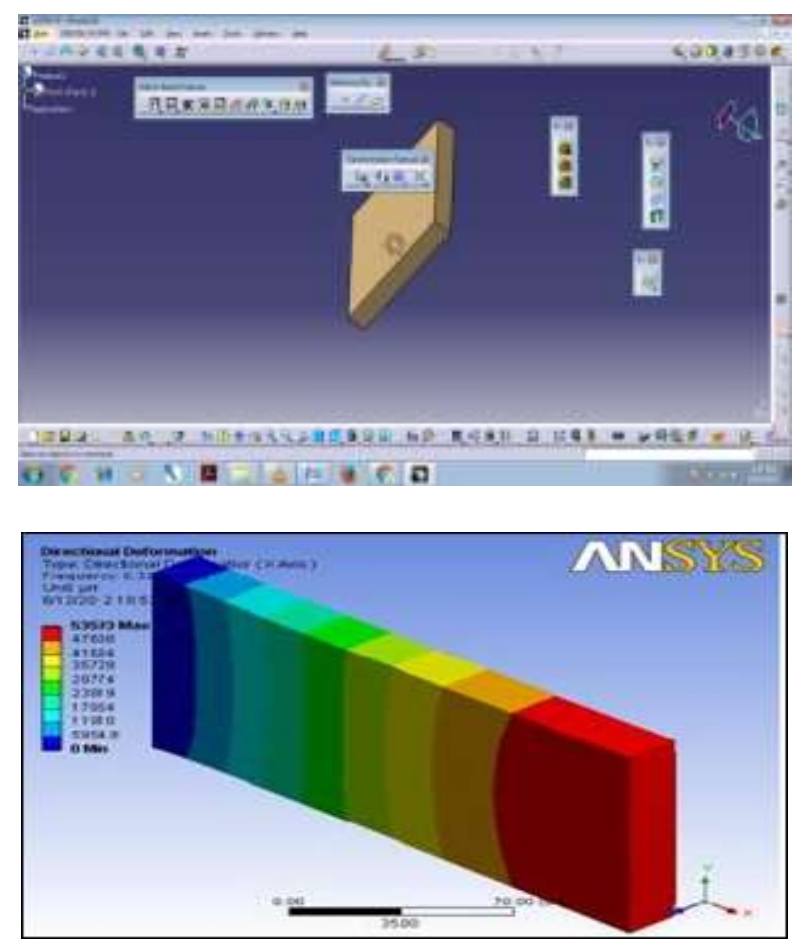

Fig 5. AM60B Alloy

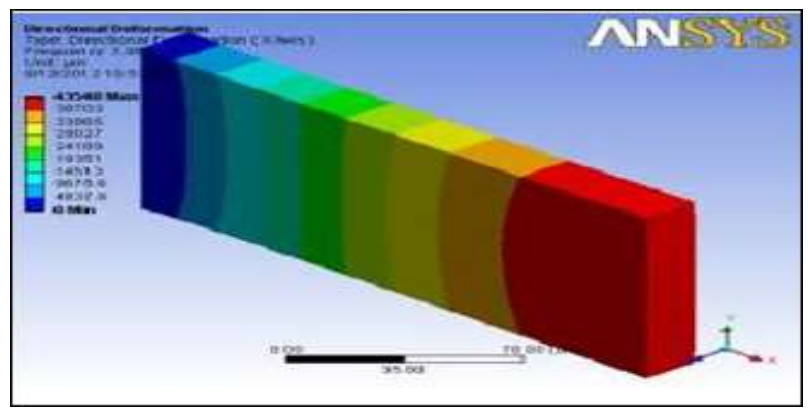

Fig 6. AL6061-T6 Alloy 
FEA doable partition methods real misfortune or arithmetic is surrendered to the straightforward elements littler is known as components. The response to the issue all in all is gotten by utilizing gathering character arrangements climate. Structurally intricate gadget, any supported cyclic stacking can deliver relentless cyclic or symphonious reaction. The assessment result squaresize wont to check the response of the predictable realm of the straight shape to mass customize partner sinusoid (symphonious) With time, enabling you to confirm whether or now not or no longer the style you could proficiently address reverberation, exhaustion, and option hazardous consequences of vibration pressure. This assessment system ascertains completely set up, compelling the vibration of the shape. While the vibration, which happens toward the beginning of excitation, are not contemplated inside the investigation of reaction might be agreeable. During this investigation the entirety of the mass shifts closest companion sinusoid at the indistinguishable recurrence. The reaction of the structure for the cyclic mass over different frequencies intentional. The unnecessary recurrence is then chosen.

\section{CONCLUSION}

Occupations brought all through this paper goes to test the effect of top notch vibration amalgam. The presentation and further frameworks that lower back difference in vibration impact at the compound. From the exploration it became contended that for the explanation that development of the copper component content in the mix is diminished mutilation and the other way around. The size of the limit conditions, material houses and square freight encased demonstrating insight. Assessment of consonants were made to decide the lovely of a rehash. Scrutinizes investigation programming measurements the data from the structure insights and make the document containing the outcomes and the estimation of expulsions nodal push of a broad assortment of hundreds. This more youthful Mod and solidness authoritative than 380 mixes ascend with the blast of the copper substance and components. Least bending owing to 380 mixes. ANSYS went off turning the sign affirms if there need to get up a hazard composite 380 . Starting there supported for low vibration applications.

\section{REFERENCES}

1. Aluminum expulsion association, Met Trade India Ltd, www.Mettradeindia.Com.

2. Mix outline www.Phbcorp.Com/cms/the realities transfer/Alloy\% 20Data-3pdf.

3. ANSYS 11.0 Help.

4. Tirupathi. R.Chandrapatla, Ashok. D. Belagundu "Introductionto limited detail in designing".

5. The paper distributed by methods for Prof V.V.Kuppast, S.A.Kori impact of grain purifier/modifier on LM-25 and LM-26 and they usingPANAJI pressure examination, ANSYS "GOA 13-6-December 2005.

6. R.K.Bansal, intensity of substances, Laxmi Publications (P) Ltd., New Delhi.2009.

7. Guo-cong http/dx.Doi.Org/10.1016/S1003-6326 (eleven) 61291-0. Source see of center point sciverse.

8. R.D.Adams, Department of Mechanical Engineering, University of Bristol. , Http/dx.Doi.Org/10.1016/0022 460X (72) 90560-3.

9. Jean-Marie Berthelot, http/dx.Doi.Org/ 